See Article page 97.

\section{Commentary: Mus uni non fidit antro... use of the modified Nuss to facilitate transplant in patients with pectus excavatum}

\author{
Aaron Eckhauser, MD, MS
}

In this issue of the Journal, Nasirov and colleagues ${ }^{1}$ steal a line from the Roman playwright Plautus to treat a young patient with Marfan syndrome with severe pectus excavatum suffering from end-stage cardiac disease. The Latin proverb Mus uni non fidit antro, or a mouse does not rely on just one hole, aptly describes the authors' creative ability to increase a very sick patient's chance of successfully receiving a lifesaving operation by simultaneously performing a modified Nuss procedure at the time of heart transplant to augment and increase intrathoracic space. The authors show for the first time that these procedures can be done concomitantly and safely in a pediatric orthotopic heart transplant.

Although patients with Marfan syndrome do not typically comprise a large portion of congenital transplant volumes, these operations can be very challenging from an anatomical perspective. A severe pectus excavatum can directly compress the right atrium or ventricle or force mediastinal structures to rotate into the left chest. Acutely, these anatomical factors can limit the ability to implant even a minimally oversized donor heart, thereby limiting a patient's donor pool based on size. Using a technique similarly described by Casamassima and colleagues, ${ }^{2}$ the authors were able to successfully implant an oversized donor heart without complication in a sick patient not otherwise a candidate for mechanical circulatory support. The pre- and postoperative computed tomography images nicely show the ameliorating effect of the Nuss bar on potential cardiac compression.

From the Division of Cardiothoracic Surgery, Department of Surgery, University of Utah, Salt Lake City, Utah.

Disclosures: Author has nothing to disclose with regard to commercial support.

Received for publication Nov 12, 2019; revisions received Nov 12, 2019; accepted for publication Nov 17, 2019; available ahead of print Jan 8, 2020.

Address for reprints: Aaron Eckhauser, MD, MS, 100 N Mario Capecchi Dr, Suite 2200, Salt Lake City, UT 84113 (E-mail: Aaron.eckhauser@hsc.utah.edu).

JTCVS Techniques 2020;1:102-3

2666-2507

Copyright (C) 2019 The Author(s). Published by Elsevier Inc. on behalf of The American Association for Thoracic Surgery. This is an open access article under the CC BY-NC-ND license (http://creativecommons.org/licenses/by-nc-nd/4.0/).

https://doi.org/10.1016/j.xjtc.2019.11.004

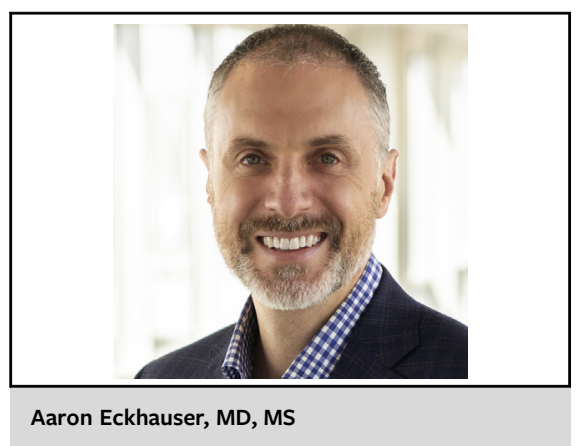

CENTRAL MESSAGE

Repair of pectus excavatum using a modified Nuss procedure during concomitant heart transplant is feasible and can creatively facilitate broadening the organ-donor pool.

Although this creative strategy can potentially increase and expand a patient's donor pool by broadening acceptable size ranges, there are several questions that remain unanswered regarding this technique. First, the incidence of Nuss bar infection remains unknown in this population. Larger series in the pediatric surgery literature report postoperative infection rates with the Nuss procedure ranging from $2 \%$ to $7 \%$. $^{3}$ Although the majority of these infections can be managed without Nuss bar removal, the risk of this complication would likely increase in an immunocompromised transplant population and warrants close follow-up. Second, in an acute postoperative setting, how would the ability to adequately perform cardiopulmonary resuscitation be affected by the Nuss bar, and if a patient does require emergent chest re-exploration, does the Nuss bar need to be removed, or can it be safely cut or divided without injuring the heart? Finally, what is the optimal metric by which to adequately determine safe and effective timing of Nuss bar removal, especially in the a chronically immunocompromised patient with impaired wound healing?

Although the potential limitations of this technique warrant continued thought and observation, I applaud the authors for their creative solution to a very time-sensitive and challenging clinical problem. Their efforts show the potential fruits of cross-specialty collaborations between general surgery and cardiothoracic surgery and highlight opportunities to learn from each other's collective expertise. 


\section{References}

1. Nasirov T, Dykes JC, Bruzoni M, Maeda K. Combined pediatric heart transplant and Nuss procedure in a patient with Marfan syndrome. J Thorac Cardiovasc Surg Tech. 2020;1:97-9.

2. Casamassima MGS, Wong LL, Papandria D, Abdullah F, Vricella LA, Cameron DE, et al. Modified Nuss procedure in concurrent repair of pectus excavatum and open heart surgery. Ann Thorac Surg. 2013;95: 1043-9.

3. Obermeyer RJ, Godbout E, Goretsky MJ, Paulson JF, Frantz FW, Kuhn MA, et al Risk factors and management of Nuss bar infections in 1717 patients over 25 years. J Pediatr Surg. 2016;51:154-8. 